\title{
Dryout-type critical heat flux in vertical upward annular flow: effects of entrainment rate, initial entrained fraction and diameter
}

\author{
Zan $\mathrm{Wu}^{1} \cdot$ Vishwas Wadekar $^{2} \cdot$ Chenglong Wang ${ }^{3} \cdot$ Bengt Sunden $^{1}$
}

Received: 13 February 2017 / Accepted: 6 July 2017 / Published online: 14 July 2017

(C) The Author(s) 2017. This article is an open access publication

\begin{abstract}
This study aims to reveal the effects of liquid entrainment, initial entrained fraction and tube diameter on liquid film dryout in vertical upward annular flow for flow boiling. Entrainment and deposition rates of droplets were included in mass conservation equations to estimate the local liquid film mass flux in annular flow, and the critical vapor quality at dryout conditions. Different entrainment rate correlations were evaluated using flow boiling data of water and organic liquids including n-pentane, iso-octane and R134a. Effect of the initial entrained fraction (IEF) at the churn-to-annular flow transition was also investigated. A transitional Boiling number was proposed to separate the IEF-sensitive region at high Boiling numbers and the IEF-insensitive region at low Boiling numbers. Besides, the diameter effect on dryout vapor quality was studied. The dryout vapor quality increases with decreasing tube diameter. It needs to be pointed out that the dryout characteristics of submillimeter channels might be different because of different mechanisms of dryout, i.e., drying of liquid film underneath long vapor slugs and flow boiling instabilities.
\end{abstract}

\section{Zan Wu}

zan.wu@energy.lth.se

1 Department of Energy Sciences, Lund University, SE-22100 Lund, Sweden

2 PS2E Institute, Paris-Saclay Research Center, 78354 Jouy-en-Josas, France

3 Science and Technology on Scramjet Laboratory, National University of Defense Technology, Changsha 410073, China

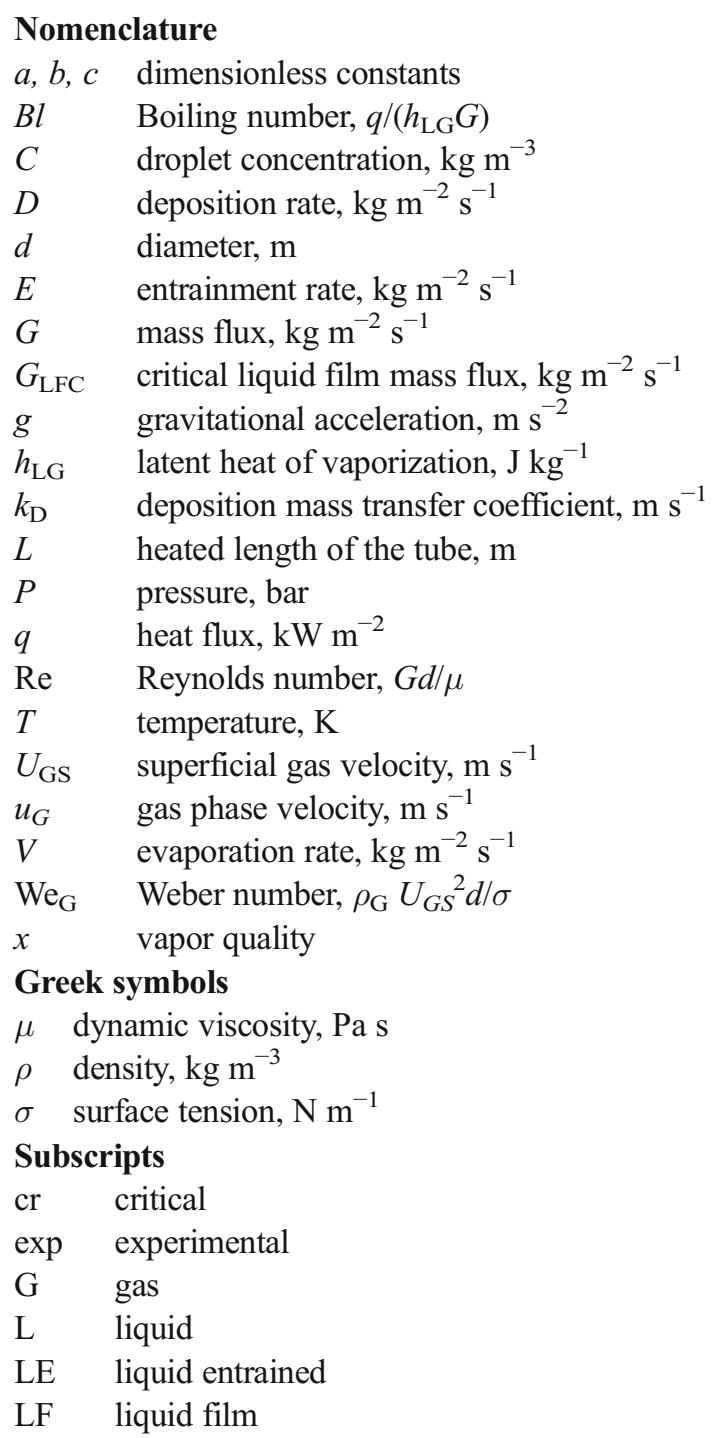


LFC critical liquid film

pre predicted

sat saturated

\section{Introduction}

Critical heat flux (CHF) represents the operational limit of the heat flux, which occurs at the transition from the nucleate boiling regime or thin film evaporation regime to the film boiling regime - a very poor heat transfer mechanism [1]. At $\mathrm{CHF}$, the liquid being in contact with the heated surface is replaced by a vapor blanket, characterized by a sharp reduction of the local heat transfer coefficient, and a sudden increase in surface temperature for heat-flux controlled systems. Therefore, CHF forms one of the most important design criteria and boundaries for boiling/evaporation-related applications. CHF can be mainly categorized into two types based on different heat transfer mechanisms: departure from nucleate boiling (DNB) and liquid film dryout. DNB generally occurs at high heat flux and low vapor quality (mainly at subcooled) conditions for bubbly flow and/or slug flow. Dryout of the liquid film on the tube wall is primarily encountered at relatively low/medium heat flux and medium/high quality conditions in churn and annular flow. Numerous experimental CHF data and predictive correlations/models have been reported in the literature, e.g., refs. [2-9]. The CHF lookup table updated by Groeneveld et al. [4] is a normalized data bank for a $8-\mathrm{mm}$ vertical tube, predicting the $\mathrm{CHF}$ as a function of pressure, mass flux and vapor quality.

It is generally true that part of the liquid phase is entrained as droplets in the vapor core in annular flow. During flow boiling, the entrained droplets are mainly caused by inlet entrainment, by the bursting of bubbles at liquid surfaces from the upstream bubbly flow and other flow patterns (e.g., slug flow, plug flow, churn flow) and by the large disturbance waves at the liquid-vapor interface due to flow boiling instabilities $[10,11]$. Different entrainment rate correlations are proposed in the literature, e.g., Paleev and Filippovich [12] and Dallman et al. [13] for horizontal adiabatic air-water flow, Hewitt and Govan [14] for non-equilibrium flows with phase change, Lopez de Bertodano et al. [15] for vertical adiabatic air-water flow, and Kataoka et al. [16] for adiabatic two-phase flow. Entrainment and deposition were implemented with some success in liquid film dryout models for the annular flow regime to estimate the dryout vapor quality or the dryout $\mathrm{CHF}$ [14]. In liquid film dryout models, some initial conditions are necessary such as the vapor quality and the initial entrained fraction at the churn-to-annular flow transition. No agreement has been achieved yet regarding the effect of the initial entrained fraction. Azzopardi [17] carried out CHF calculations at a number of initial entrained fractions in the range of
0.01 to 0.99 . A value of 0.7 for initial entrained fraction at the onset of annular flow was assumed by Ahmad [18].

Effect of tube diameter on dryout is less understood due to scarcity of systematic experimental work, despite the large amount of available CHF data in the literature. It is difficult to find a systematic set of data, with similar operating conditions at different tube diameters for comparison [19]. One of the earliest studies of diameter effect on CHF was carried out by Becker [20] in Sweden in 1965, followed by Boltenko et al. [21], Celata et al. [22], Tanase et al. [23] etc. There is no clear and consistent view of the effect of diameter on CHF. Table 1 summarizes the main phenomena and the corresponding mechanisms for the diameter effect on CHF in conventional tubes. In annular flow, generally $\mathrm{CHF}$ increases with decreasing tube diameter. The probable reason for this trend for the dryouttype CHF might be that significant liquid entrainment and rough wavy liquid-vapor interface are more likely to occur in large diameter tubes than in small diameter tubes. Flow visualization studies indicate that there is significant entrainment in the annular two-phase flow for large diameter tubes and the liquid-vapor interface is very chaotic with vigorous activity of droplet entrainment and deposition processes. More recent flow visualization studies (e.g., Karayiannis et al. [24], Harirchian and Garimella [25]) indicate that for flow boiling in small diameter tubes, there is virtually no entrainment and the liquid film interface is relatively smooth. These observations provide compelling evidence that droplet entrainment would increase with increasing tube diameter and hence reduce the dryout quality as the tube diameter increases for dryout-type CHF. It is noted that the features indicated in Table 1 might not be applicable for micro/minichannels mainly due to the following reasons. Firstly, explosive bubble growth and possible flow instability and flow reversal tend to induce premature $\mathrm{CHF}$ [1]. Secondly, bubbles tend to be confined and coalesced to form elongated bubbles. The mechanism of intermittent dryout underneath the elongated bubbles probably differs from the DNB-type CHF in conventional tubes. Thirdly, liquid film around the wall ruptures due to departure from thermalhydraulic equilibrium in microchannels. In addition, the bubble-tube interaction at smaller scales is potentially more pronounced compared to large-scale tubes. Moreover, roughness size not obvious in conventional tubes might need to be considered compared to the small diameter of microchannels.

The present work aims to (1) evaluate different entrainment rate correlations, (2) study the effect of initial entrained fraction at the churn-to-annular flow transition and (3) the effect of tube diameter on liquid film dryout in vertical upward annular flow.

\section{Liquid film dryout in annular flow}

The local value of the liquid film mass flux in annular flow can be estimated by integration of the mass conservation equation 
Table 1 The diameter effect on CHF for conventional tubes

\begin{tabular}{lll}
\hline CHF types & Phenomena in smaller diameter tubes & Mechanisms for higher CHF in smaller diameter tubes \\
\hline $\begin{array}{l}\text { DNB-type CHF at subcooled and low vapor quality } \\
\text { conditions (bubbly and/or slug flow) }\end{array}$ & $\begin{array}{l}\text { Thinner bubble boundary layer } \\
\text { Lower void fraction within bubble } \\
\text { layer } \\
\text { Higher temperature and velocity } \\
\text { gradients of the boundary layer } \\
\text { Interfacial friction inversely } \\
\text { proportional with Reynolds number }\end{array}$ & $\begin{array}{c}\text { Better heat transfer } \\
\text { Easier re-entry of liquid replenishment } \\
\text { Higher condensation rate at bubble tip, slower bubble } \\
\text { generation and easier bubble detachment } \\
\text { Better heat transfer due to increased liquid-vapor inter- } \\
\text { actions }\end{array}$ \\
$\begin{array}{c}\text { Thinner liquid film, i.e., lower liquid } \\
\text { mass flow rate in the film }\end{array}$ & $\begin{array}{c}\text { Lower liquid entrainment rate, suppressed nucleate } \\
\text { boiling, higher evaporation rate } \\
\text { (churn and annular flow) }\end{array}$ \\
& $\begin{array}{c}\text { Larger temperature gradient in the } \\
\text { liquid film }\end{array}$ & $\begin{array}{c}\text { Better heat transfer } \\
\end{array}$ \\
\hline
\end{tabular}

from the churn-to-annular flow transition point to the dryout point (where the liquid film mass flux equals zero) [14]:

$\frac{d}{d z} G_{L F}=\frac{4}{d}\left(D-E-V_{L F}\right)$

where $D, E$ and $V_{\mathrm{LF}}$ indicate the deposition rate, the entrainment rate and the liquid film evaporation rate (mass per unit channel surface area per unit time), respectively. $D$ is calculated by [14]:

$D=K_{D} C$

The droplet concentration $C$ in the gas core is calculated on a homogeneous basis as:

$C=\frac{G_{L E}}{\frac{G_{G}}{\rho_{G}}+\frac{G_{L E}}{\rho_{L}}}$

The deposition mass transfer coefficient $\left(K_{\mathrm{D}}\right)$ was correlated in the form [14]:

$K_{D}=\left\{\begin{array}{cc}0.18\left(\frac{\sigma}{\rho_{G} d}\right)^{0.5} & \text { if } \frac{C}{\rho_{G}} \leq 0.3 \\ 0.083\left(\frac{\sigma}{\rho_{G} d}\right)^{0.5}\left(\frac{\rho_{G}}{C}\right)^{0.65} & \text { if } \frac{C}{\rho_{G}}>0.3\end{array}\right.$

Hewitt and Govan [14] proposed the following expression to calculate the entrainment rate for adiabatic two-phase flow and flow with evaporation:

$E=5.75 \times 10^{-5} G x\left[\frac{d \rho_{L}}{\sigma \rho_{G}^{2}}\left(G_{L F}-G_{L F C}\right)^{2}\right]^{0.316}$ where $G_{\mathrm{LFC}}$ is the minimum liquid film mass flux for the onset of droplet entrainment, given by [14]:

$G_{L F C}=\frac{\mu_{L}}{d} \exp \left[5.8504+.04249\left(\frac{\mu_{G}}{\mu_{L}}\right)\left(\frac{\rho_{L}}{\rho_{G}}\right)^{0.5}\right]$

Lopez de Bertodano et al. [15] proposed an entrainment rate correlation based on air-water experiments in a vertical tube of an internal diameter of $9.5 \mathrm{~mm}$.

$E=7.42 \times 10^{-7} \frac{\mu_{L}}{d}\left[W e_{G}\left(\frac{\rho_{L}-\rho_{G}}{\rho_{G}}\right)^{0.5}\left(\operatorname{Re}_{L F}-\operatorname{Re}_{L F C}\right)\right]^{n}\left(\frac{\mu_{G}}{\mu_{L}}\right)^{0.26}$

where the minimum Reynolds number for the onset of droplet entrainment of the liquid film is

$\operatorname{Re}_{\mathrm{LFC}}=80$

The gas Weber number $\mathrm{We}_{\mathrm{G}}$ can be calculated by

$W e_{G}=\frac{\rho_{G} U_{G S}^{2} d}{\sigma}$

Later, based on air-water and R-113 entrainment rate data, Lopez de Bertodano et al. [26] developed a new model to estimate the entrainment rate

$E=5 \times 10^{-8} \frac{\mu_{L}}{d}\left(\operatorname{Re}_{L F}-\operatorname{Re}_{L F C}\right) W e_{G}\left(\frac{\rho_{L}}{\rho_{G}}\right)^{0.5}$

Dallman et al. [13] correlated the entrainment rate from a liquid film for air-water upflow as follows

$E=9.5 \times 10^{-7} d\left(G_{L F}-G_{L F C}\right) \mu_{G}^{2} \rho_{G}^{0.5} \rho_{L}^{0.5}$ 
where $G_{\mathrm{LFC}}$ is given by

$G_{L F C}=0.184 / d$

The following correlation can indicate the transition from churn flow to annular flow.

$U_{G S} \sqrt{\frac{\rho_{G}}{g d\left(\rho_{L}-\rho_{G}\right)}} \geq 1$ for annular flow

The above modelling of film dryout is essentially based on adiabatic deposition and entrainment rates. One would guess that the deposition rate depends on droplet concentration and hence same for adiabatic or boiling situation. However, for entrainment rate, there could be significant difference between the two situations. Compared to adiabatic situation, the vapor generation flux during the boiling process tends to "stir" the liquid-vapor interface and promote liquid entrainment. The

\section{a}
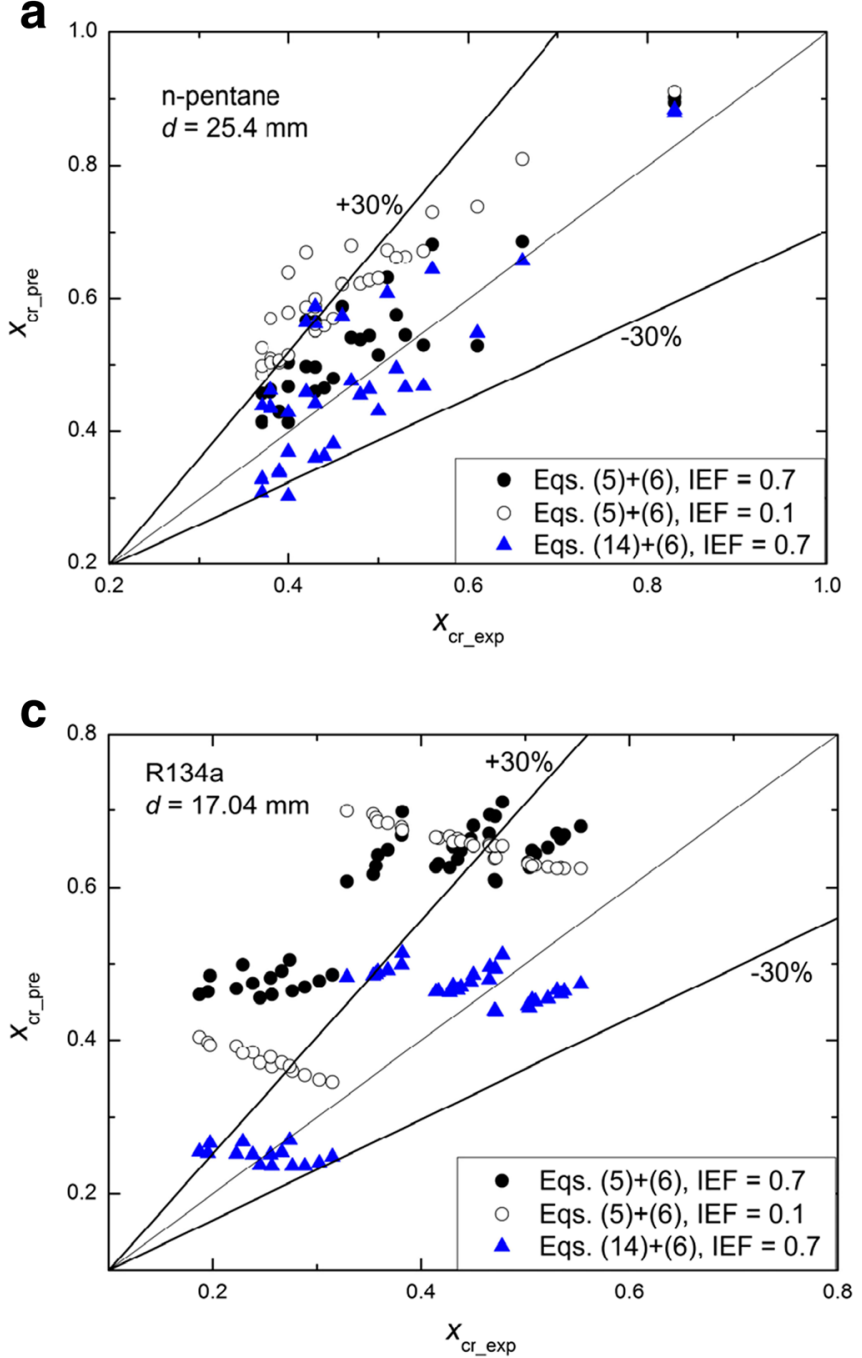

Boiling number $(\mathrm{Bl})$ is a good measure of vapor generation flux. Therefore, an additional term of the Boiling number might be adopted in the entrainment rate correlation to increase the entrainment for flow boiling. The additional term of Boiling number will be incorporated in the entrainment rate correlation Eq. (5) for organic liquids. The additional Boiling number term will not be used for water as the Hewitt and Govan model [14] has been extensively validated for steamwater systems. For organic liquids, a Boiling number term has been added to Eq. (5) as follows:

$E=5.75 \times 10^{-5} G x\left[\frac{d \rho_{L}}{\sigma \rho_{G}^{2}}\left(G_{L F}-G_{L F C}\right)^{2}\right]^{0.316}\left(1+a x^{-1.2} \mathrm{Bl}^{0.1}\right)$

Equation (14) shows that an additional term in the form of $\left(1+a x^{\mathrm{b}} \mathrm{Bl}^{\mathrm{c}}\right)$ has been used with $a>0, b<-1.0$ and $c>0$. Such an additional Boiling number form has a value larger than

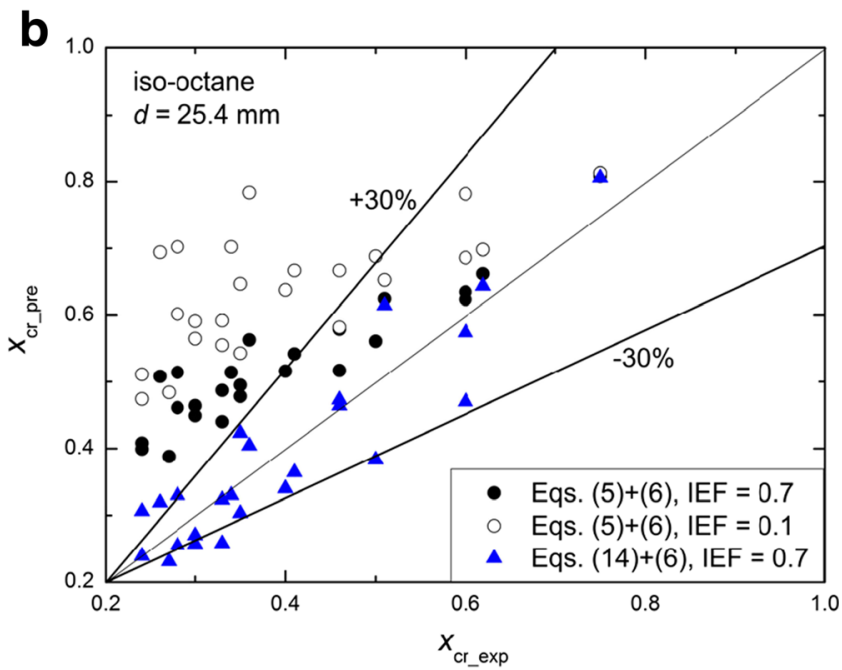

Fig. 1 Evaluation of the Hewitt and Govan model [14] (Eqs. (5) + (6)) and the modified model (Eqs. (14) + (6)) for n-pentane and iso-octane data of Kandlbinder [27] and for R134a data of Kim and Chang [28] at two different IEF values: a n-pentane; b iso-octane; and $\mathbf{c}$ R134a 


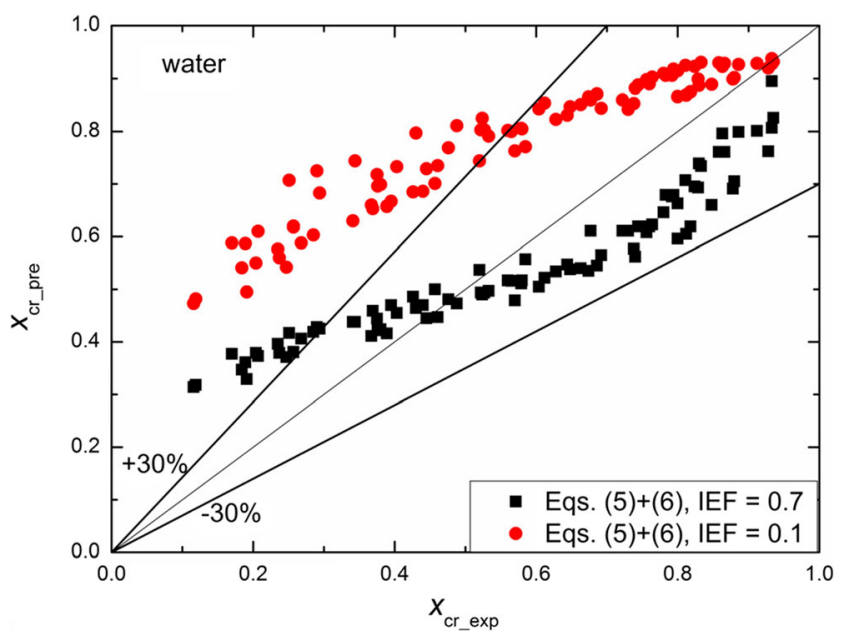

Fig. 2 Evaluation of the Hewitt and Govan model [14] (Eqs. (5) + (6)) for water data of Becker [20] at two different IEF values
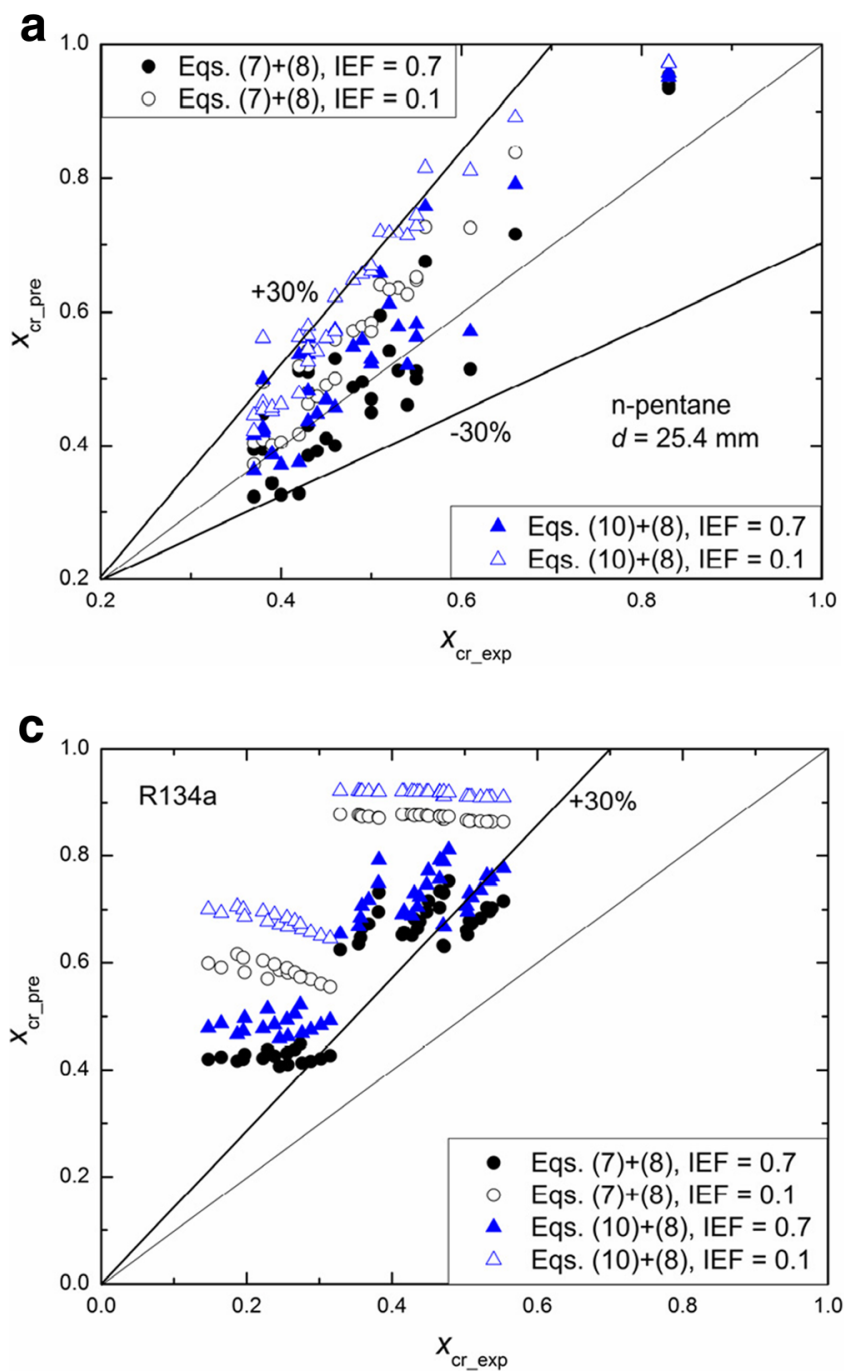

Fig. 3 Evaluation of the Lopez de Bertodano et al. model [15] (Eqs. (7) + (8)) and the Lopez de Bertodano et al. model [26] (Eqs. (10) + (8)) for npentane and iso-octane data of Kandlbinder [27], for R134a data of Kim unity, which indicates that flow boiling increases the droplet entrainment.

\section{Evaluation of entrainment rate correlations}

Experimental dryout data from Kandlbinder [27] for flow boiling of iso-octane and n-pentane, from Kim and Chang [28] for flow boiling of R134a and from Becker [20] for flow boiling of water were used to evaluate the entrainment rate correlations. In Kandlbinder [27], the dryout data were obtained for flow boiling of iso-octane and n-pentane in a long vertical tube with an inner diameter of $25.4 \mathrm{~mm}$. The experimental ranges for saturation pressure, mass flux and heat flux are 2.06-9.99 bar, $191-522 \mathrm{~kg} \mathrm{~m}^{-2} \mathrm{~s}^{-1}$ and $29-100.5 \mathrm{~kW} \mathrm{~m}^{-2}$, respectively. In Kim and Chang [28], the dryout-type CHF data were obtained for flow boiling of R134a flowing upward
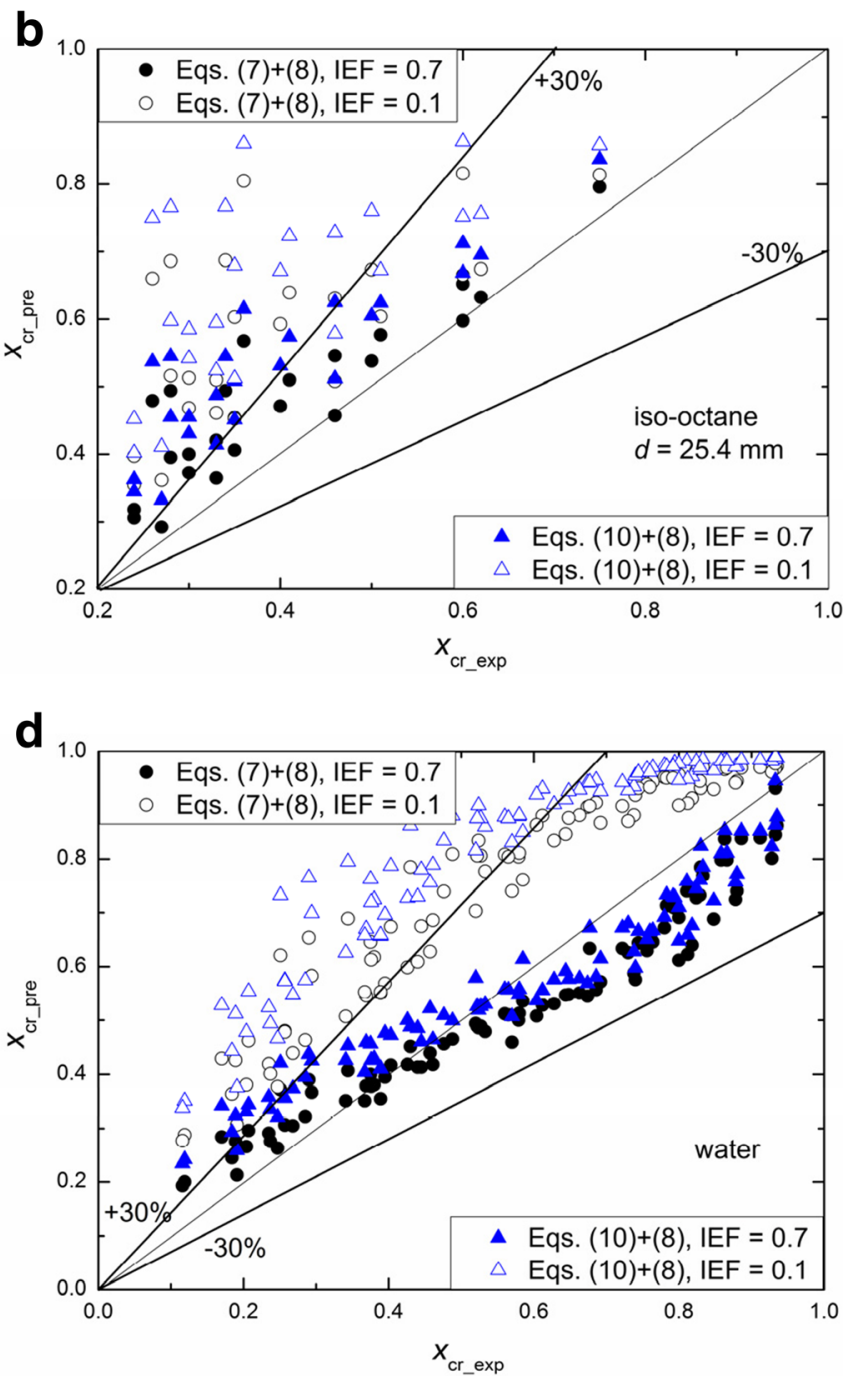

and Chang [28] and for water data of Becker [20] at two different IEF values: (a) n-pentane; (b) iso-octane; (c) R134a; and (d) water 
in a uniformly heated vertical tube with an inner diameter of $17.04 \mathrm{~mm}$ and a heated length of $3 \mathrm{~m}$, and the corresponding experimental ranges for saturation pressure, mass flux and heat flux are 13.0-23.9 bar, 285-1300 $\mathrm{kg} \mathrm{m}^{-2} \mathrm{~s}^{-1}$, and 35$140 \mathrm{~kW} \mathrm{~m}^{-2}$, respectively. For Becker [20], the dryout data were for flow boiling of water in vertical tubes of different diameters. The experimental data at a saturation pressure of 50 bar were selected and the corresponding experimental ranges for mass flux, heat flux and diameter are 255$3795 \mathrm{~kg} \mathrm{~m}^{-2} \mathrm{~s}^{-1}, 1002-4590 \mathrm{~kW} \mathrm{~m}^{-2}$, and $3.93-19.93 \mathrm{~mm}$, respectively. For all the three data sets, only the data points with $L / d$ ratios larger than 150 were selected [7].

Figure 1 shows the estimations of the Hewitt and Govan model [14] at two different values of initial entrained fraction (IEF) at the churn-to-annular flow transition. Information on the amount of entrained liquid at the transition from churn to annular flow boundary is required as it is the starting point of integration of Eq. (1). Similar to Ahmad [18], an IEF of 0.7 was used. An IEF value of 0.1 was also used in this work for comparison to investigate the effects of IEF on liquid film dryout in annular flow, which will be discussed later. On one hand, it can be noticed from Fig. 1a that the Hewitt and Govan model [14] (Eqs. (5) and (6)) with an IEF value of 0.7 could capture most of the data points of n-pentane within the $\pm 30 \%$ error band. On the other hand, the Hewitt and Govan model [14] tends to over-predict the data points of iso-octane and R134a, especially at low dryout vapor qualities. Figure 2 shows predictions of the Hewitt and Govan model [14] for water data of Becker [20] at two different IEF values. In general, the Hewitt and Govan model [14] can predict most of the data points of water within the $\pm 30 \%$ error band, only with a slight over-prediction at low dryout vapor qualities. The Hewitt and Govan model [14] was generalized and evaluated based on a large water database. Therefore, it generally shows very good estimations for water data. Besides, from Fig. 1a, it still shows some predictive potential for organic liquids.

As can be seen from Fig. $1 \mathrm{~b}$ and c, the Hewitt and Govan model [14] using Eq. (5) tends to over-predict the data for isooctane and R134a, especially at low dryout vapor qualities. Therefore, in Eq. (14) a vapor quality term with a power index less than -1.0 was used, which gives a larger entrainment rate at a lower vapor quality. When $b=-1.2$ and $c=0.1$, most of the predicted dryout quality values for n-pentane, iso-octane and R134a are almost evenly distributed within the $\pm 30 \%$ error band at IEF $=0.7$ with an $a$ value of 1.0, 1.5 and 2.0, respectively. Such a trial indicates that an additional term with a form similar to Eq. (14) might improve the predictive capability of liquid film dryout by considering the effect of flow boiling on droplet entrainment. More specific values of $a, b$ and $c$ could be obtained if a large database had been used.

Figure 3 shows the predictive abilities of the Lopez de Bertodano et al. model [15] (Eqs. (7) + (8)) and the Lopez de Bertodano et al. model [26] (Eqs. (10) + (8)) at two IEF values. As shown in Fig. 3, there is only a small difference between the predicted values based on Eqs. (7) + (8) and those based on Eqs. (10) + (8). The two entrainment rate equations, i.e., Eq. (7) and Eq. (10), have a similar form. Moreover, it seems that the both models, i.e., [15] and [26], with an IEF value of 0.7 , can predict most of the data points of n-pentane and water. The iso-octane data and the R134a data were largely over-predicted by models [15] and [26]. Similar to Figs. 1 and 2, an IEF value of 0.1 generally gives somewhat higher predictive values compared to an IEF value of 0.7 .

The estimations of the Dallman et al. model [13] are shown in Fig. 4. The Dallman et al. model is unable to capture the data reasonably by largely over-predicting many of the data points.

\section{Effect of the initial entrained fraction (IEF) at the churn-to-annular flow transition on liquid film dryout}

A lower IEF value indicates a lower amount of entrained liquid in the gas core and thus a larger liquid film mass flux at the churn-annular transition, which in general produces a higher dryout vapor quality than that at a higher IEF value, as shown in Figs. 1, 2, 3 and 4. However, this is not always the case. Depending on the operating conditions such as mass fluxes and heat fluxes, the effects of IEF on the liquid film dryout quality are different. For instance, as seen in Figs. 1, 3 and 4, some of the data points of n-pentane and iso-octane calculated by the same model for IEF values of 0.1 and 0.7 are approximately overlapped. Based on this

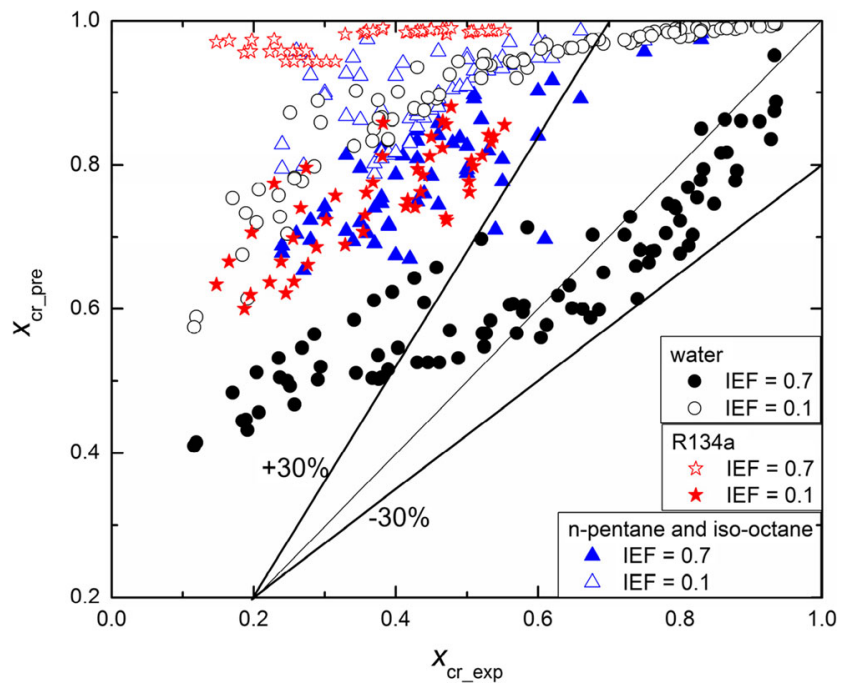

Fig. 4 Evaluation of the Dallman et al. model [13] (Eqs. (11) + (12)) for $\mathrm{n}$-pentane and iso-octane data of Kandlbinder [27], for R134a data of Kim and Chang [28] and for water data of Becker [20] at two IEF values 

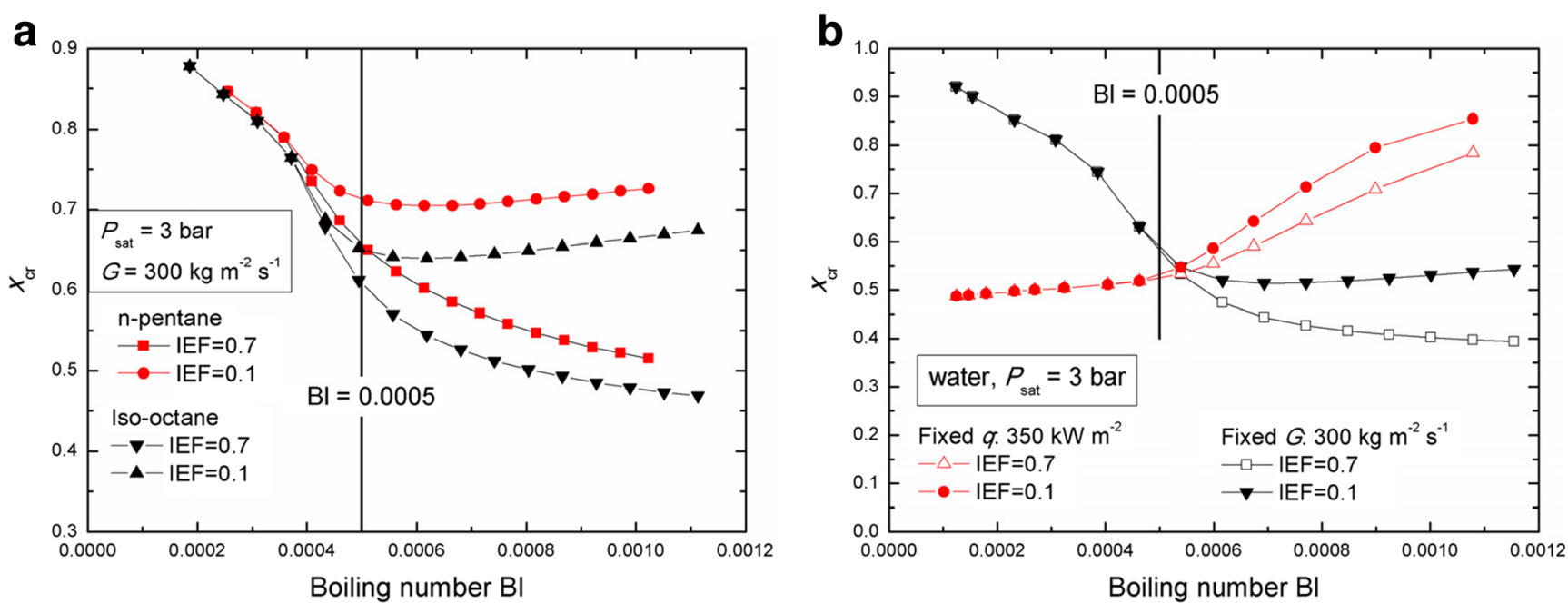

Fig. 5 The effects of IEF on dryout vapor quality versus the Boiling number: a n-pentane and iso-octane; and $\mathbf{b}$ water

finding, it seems that there exist an IEF-sensitive region and an IEF-insensitive region.

By screening the data, it is found that the Boiling number can be used as an index for IEF effects on dryout quality, as shown in Fig. 5. There exists a transitional Boiling number which ranges from 0.0004 to 0.0006 . For simplicity, 0.0005 can be used as the transitional Boiling number. If the Boiling number is larger than the transitional Boiling number, IEF effects need to be considered to estimate the dryout quality. Dryout qualites are insensitive to IEF values when the Boiling number is lower than the transitional Boiling number.

For low Boiling numbers, the heat flux is comparatively low and the mass flux is comparatively high. The liquid film evaporation rate $V_{\mathrm{LF}}$ is comparably low and thus the liquid film dryout might occur "far" from the churn-to-annular flow transition. Therefore, there is a sufficient length to achieve a droplet entrainment/deposition equilibrium. Thus, the effects of IEF become negligible. On the contrary, for large Boiling numbers, the liquid film evaporation rate $V_{\mathrm{LF}}$ is comparably high and

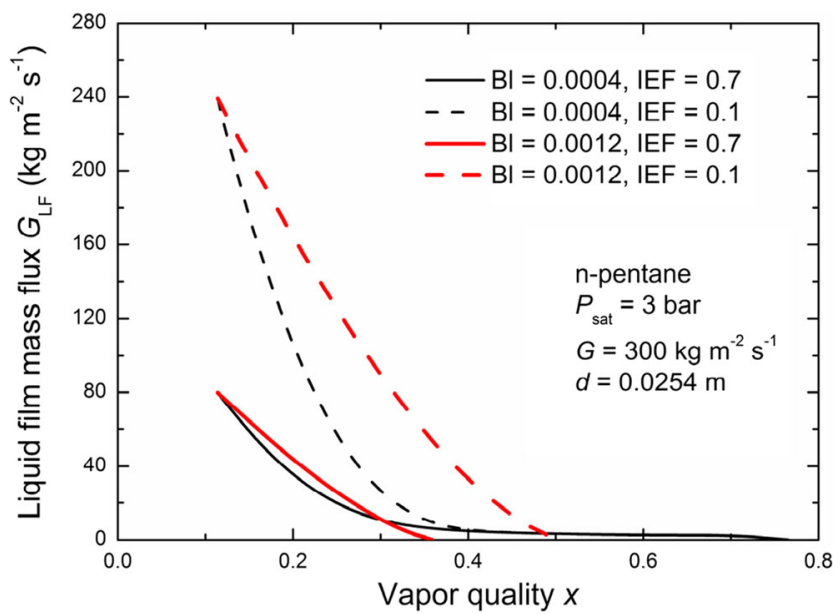

Fig. 6 Liquid film mass flux distributions $\left(G_{\mathrm{LF}}\right)$ in annular flow versus vapor quality for n-pentane causes liquid film dryout "near" the churn-to-annular flow transition at a relatively low vapor quality. Thus, the dryout quality is sensitive to the IEF for large Boiling numbers.

Figure 6 shows the local liquid film mass flux versus the local vapor quality for n-pentane. The liquid film mass flux approaches zero as vapor quality increases. For a low Boiling number of 0.0004 , although the IEF values affect the variations of the liquid film mass flux versus vapor quality, the liquid film mass flux approaches zero at the same point for the two different IEF values. For a high Boiling number of 0.0012 larger than the transitional Boiling number, the IEF values affect both the variation of the liquid film mass flux and the location of the zero $G_{\mathrm{LF}}$ point, i.e., the dryout point. Other organic liquids such as iso-octane and R134a also present similar trends as n-pentane.

Normally, liquid film dryout occurs at low vapor qualities for flows with high Boiling numbers. However, it should be noted from Figs. 1, 2, 3 and 4 that the dryout quality tends to be over-predicted at low vapor qualities (i.e., at high Boiling

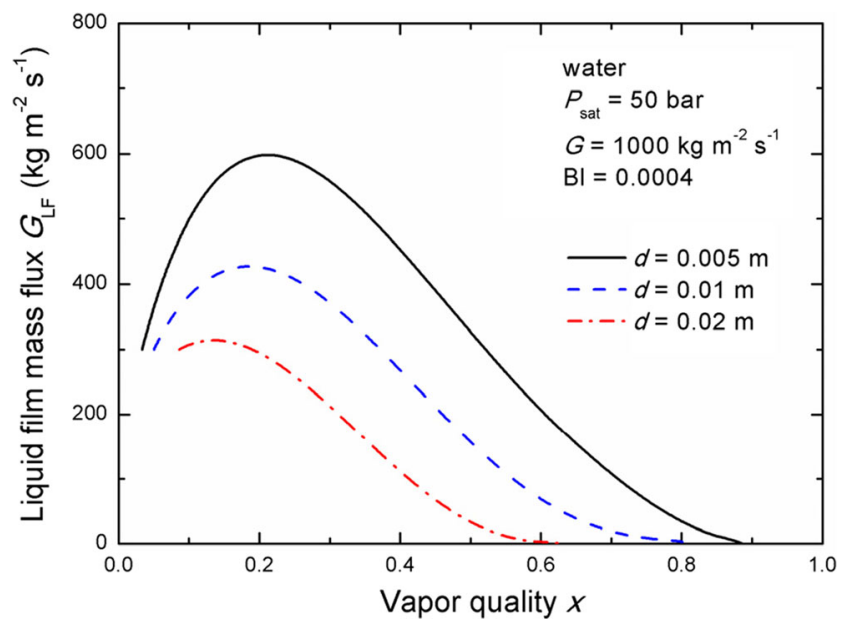

Fig. 7 Liquid film mass flux distributions $\left(G_{\mathrm{LF}}\right)$ in annular flow at different tube diameters for water. The IEF value was set as 0.7 

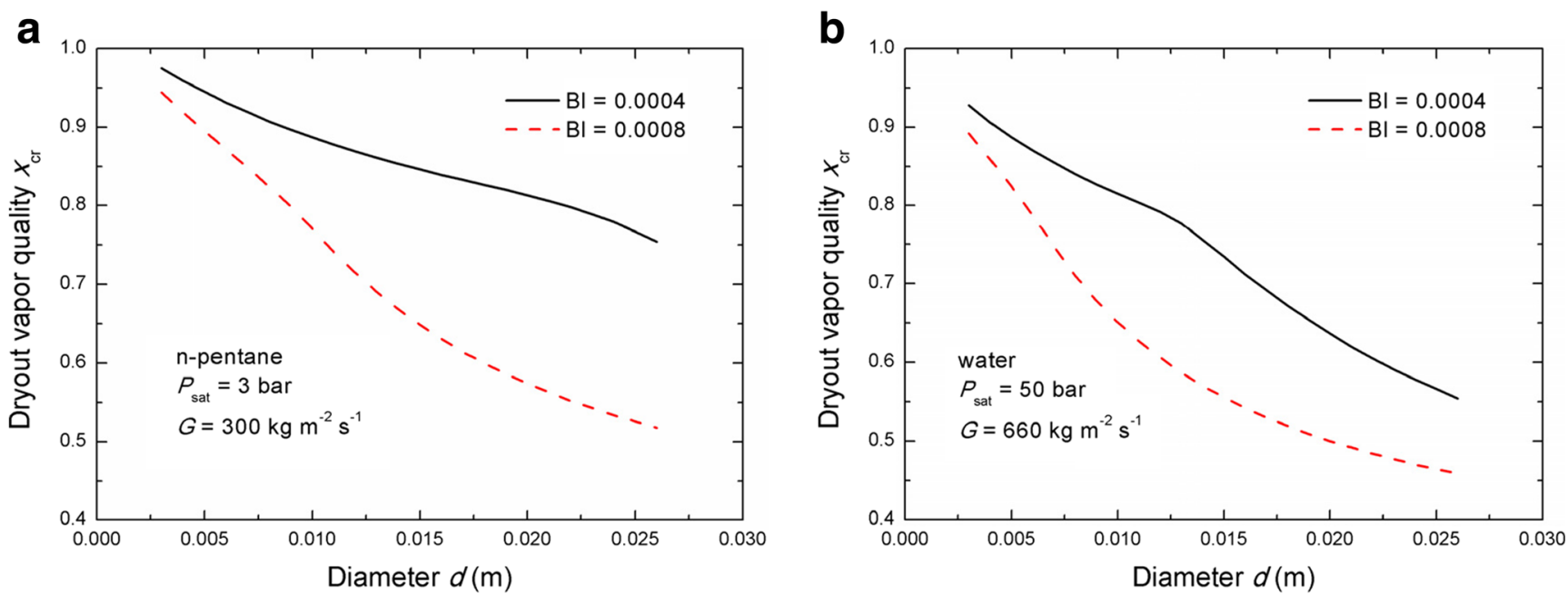

Fig. 8 Effects of diameter on dryout vapor quality based on the Hewitt and Govan model [14]: a n-pentane; and $\mathbf{b}$ water. The IEF value was set as 0.7

numbers). A probable reason for the over-prediction at high Boiling numbers might be the limitation of the entrainment rate correlations. The entrainment rate correlations are mainly based on the entrainment mechanism of shearing off of roll waves or the Kelvin-Helmholtz interface instability. At high Boiling numbers, nucleate boiling might occur in the liquid film and bubbles might burst through the liquid-vapor interface, carrying liquid into the gas core, especially for largediameter tubes. Besides, the evaporation flux may inhibit droplet deposition. Therefore, the net entrainment rate is higher than the predicted values and thus the real dryout quality is over-predicted.

\section{Effect of diameter on liquid film dryout}

Figure 7 shows the local liquid film mass flux versus local vapor quality along the tube for water at 50 bar for three

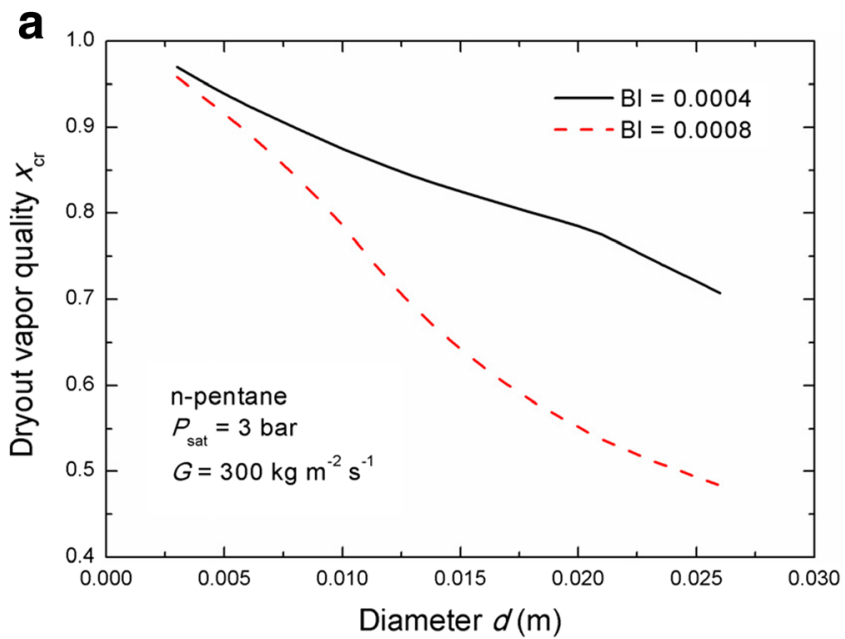

different diameters. At relatively high vapor qualities, the liquid film mass flux decreases with vapor quality until the liquid film dries out at the dryout vapor quality. The local liquid film mass flux in a small-diameter tube increases first as the amount of deposited liquid exceeds the entrained and evaporated liquid. Then the liquid film mass flux decreases as the entrained and evaporated liquid exceeds the deposited liquid. As shown in Fig. 7, smaller tube diameters would tend to have a higher dryout vapor quality for stable flow boiling when the other operating parameters are fixed. One of the main reasons is that the entrainment rate is lower in smaller tubes and the deposition rate is higher in smaller tubes than those in larger tubes. Therefore, there is less droplet entrainment in the vapor core and a larger liquid film mass flux in smaller tubes, in the high quality region.

Figures 8 and 9 present the relationship between dryout vapor quality and tube diameter at different Boiling numbers for the Hewitt and Govan model [14] and the Lopez de

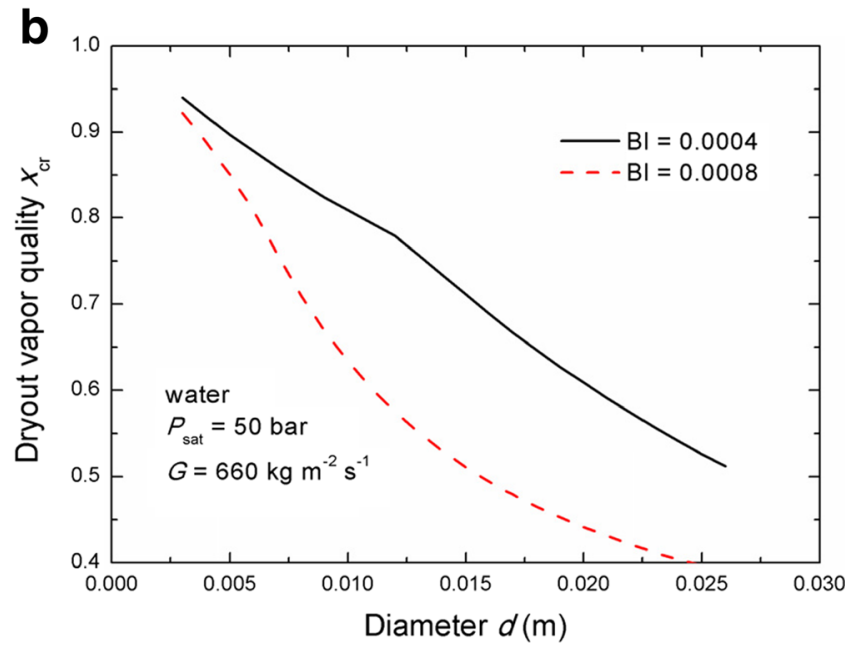

Fig. 9 Effects of diameter on dryout vapor quality based on the Lopez de Bertodano et al. model [15]: a n-pentane; and $\mathbf{b}$ water. The IEF value was set as 0.7 
Bertodano et al. model [15], respectively. As shown in Figs. 8 and 9 , the dryout vapor quality increases when the tube diameter decreases. For stable flow boiling flowing upwards in long vertical tubes, smaller tubes can achieve higher dryout vapor qualities. As explained earlier, the main reason is less liquid entrainment in smaller tubes than larger tubes. The waviness of the liquid-vapor interface is much smaller due to stronger surface tension in small channels than the large disturbance waves in large channels. A probable evidence is that one can observe smooth liquid-vapor interfaces in many flow pattern images in the literature for stable flow boiling in microchannels. Besides, when the diameter decreases, the rate of increase of dryout quality is larger at high Boiling numbers than that at low Boiling numbers, which is due to the large difference in dryout vapor quality between small and large tubes at high Boiling numbers.

However, it does not mean that the dryout vapor quality will continue to increase when the diameter decreases further to microchannels. The dryout vapor quality might again decrease in microchannels because the liquid film underneath the long vapor slugs or elongated/confined bubbles might dry out to cause intermittent dryout or premature critical heat flux at low vapor qualities $[29,30]$. Besides, the flow boiling instabilities in micro/minichannels accelerate premature critical heat flux and degrade heat transfer quickly.

\section{Conclusions}

Dryout models implemented with appropriate entrainment and deposition models are of general use. Entrainment and deposition rates of droplets were included in mass conservation equations to estimate the local liquid film mass flux in vertical upward annular flow, and the critical vapor quality at dryout conditions. Different entrainment rate correlations were evaluated based on the n-pentane and iso-octane data of Kandlbinder [27], the R134a data of Kim and Chang [28] and the water data of Becker [20]. The Hewitt and Govan model [9] and the two correlations developed by Lopez de Bertodano et al. $[15,26]$ can capture most of the data points of n-pentane and water within the $\pm 30 \%$ error band. For organic liquids, an additional term of Boiling number has been added to the entrainment rate correlation Eq. (5) to increase the entrainment for flow boiling, which considerably improves the predictive capability of liquid film dryout for organic liquids.

Information on the amount of entrained liquid at the transition from churn to annular flow boundary is required as it is the starting point of integration of the mass conservation equation. Effect of the initial entrained fraction (IEF) at the churnannular transition was outlined. A transitional Boiling number was proposed to separate the IEF-sensitive region at high
Boiling numbers and the IEF-insensitive region at low Boiling numbers.

In addition, the diameter effect on dryout vapor quality was examined. In general, the dryout vapor quality increases with decreasing tube diameter. A possible reason is that there is less droplet entrainment in smaller tubes and thus larger liquid film mass flux in smaller tubes. Less entrainment in the vapor core in smaller tubes was also evidenced by flow visualization studies in the literature. It should be noted that the above statement is only applicable for "conventional diameter" tubes. The dryout vapor quality will generally not continue to increase with decreasing diameters in microchannels due to intermittent dryout of liquid film underneath the long vapor slugs and flow boiling instability.

Acknowledgements The financial support from the Swedish National Research Council is gratefully acknowledged. One of the authors (VW) would like to thank PS2E Institute for the support in carrying out this work.

\section{Compliance with ethical standards}

Conflict of interest On behalf of all authors, the corresponding author states that there is no conflict of interest.

Open Access This article is distributed under the terms of the Creative Commons Attribution 4.0 International License (http:// creativecommons.org/licenses/by/4.0/), which permits unrestricted use, distribution, and reproduction in any medium, provided you give appropriate credit to the original author(s) and the source, provide a link to the Creative Commons license, and indicate if changes were made.

\section{References}

1. Wu Z, Sundén B (2014) On further enhancement of single-phase and flow boiling heat transfer in micro/minichannels. Renew Sustain Energ Rev 40:11-27

2. Nejat Z, Mottaghian R (1980) Analytical study of critical heat flux in vertical tubes with small length to diameter ratios. Heat Mass Transf 14(1):43-47

3. Lin KW, Lee CH, Hourng LW, Hsu JC (1994) A theoretical and experimental study on subcooled flow boiling at high heat flux. Heat Mass Transf 29(5):319-327

4. Groeneveld DC, Shan JQ, Vasić AZ, Leung LKH, Durmayaz A, Yang J, Cheng SC, Tanase A (2007) The 2006 CHF look-up table. Nucl Eng Des 237:1909-1922

5. Hewitt GF (1978) Critical heat flux in flow boiling. Proc Sixth International Heat Transfer Conference, pp 143-171

6. Hall DD, Mudawar I (2000) Critical heat flux (CHF) for water flow in tubes - I. Compilation and assessment of world CHF data. Int J Heat Mass Transf 43:2573-2604

7. Wu Z, Li W (2011) A new predictive tool for saturated critical heat flux in micro/mini-channels: effect of the heated length-to-diameter ratio. Int J Heat Mass Transf 54(13):2880-2889

8. Basu S, Ndao S, Michna GJ, Peles Y, Jensen MK (2011) Flow boiling of R134a in circular microtubes - part II: study of critical heat flux condition. ASME J Heat Transfer 133(5):051503 
9. Younes A, Hassan I (2015) Modeling of dry-out incipience for flow boiling in a circular microchannel at a uniform heat flux. ASME J. Heat Transfer 137(2):021502

10. Ishii M, Grolmes MA (1975) Inception criteria for droplet entrainment in two-phase concurrent film flow. AICHE J 21(2):308-318

11. Ding Y, Kakac S, Chen XJ (1995) Dynamic instabilities of boiling two-phase flow in a single horizontal channel. Exp Thermal Fluid Sci 11(4):327-342

12. Paleev II, Filippovich BS (1966) Phenomena of liquid transfer in two-phase dispersed annular flow. Int J Heat Mass Transf 9(10): 1089-1093

13. Dallman JC, Laurinat JE, Hanratty TJ (1984) Entrainment for horizontal annular gas-liquid flow. Int J Multiphase Flow 10(6):677689

14. Hewitt GF, Govan AH (1990) Phenomenological modelling of nonequilibrium flows with phase change. Int J Heat Mass Transf 33(2): 229-242

15. Lopez de Bertodano MA, Jan CS, Beus SG (1996) Annular flow entrainment rate experiment in a vertical pipe, no. WAPD-T-3107. Bettis Atomic Power Lab, West Mifflin

16. Kataoka I, Ishii M, Nakayama A (2000) Entrainment and deposition rates of droplets in annular two-phase flow. Int J Heat Mass Transf 43(9): 1573-1589

17. Azzopardi BJ (1996) Prediction of dryout and post-burnout heat transfer with axially non-uniform heat input by means of an annular flow model. Nucl Eng Des 163(1-2):51-57

18. Ahmad M (2011) Critical Heat Flux and Associated Phenomena in Forced Convective Boiling in Nuclear Systems. Ph.D thesis, Imperial College London

19. Cheng X, Erbacher FJ, Müller U, Pang FG (1997) Critical heat flux in uniformly heated vertical tubes. Int J Heat Mass Transf 40:2929 2939
20. Becker KM (1965) An analytical and experimental study of burnout conditions in vertical round ducts. Nukleonika 9:257-270

21. Boltenko EA, Vinogradov VN, Katan IB (1989) Effect of tube diameter on CHF at various two phase flow regimes. Report IPE1989

22. Celata GP, Mishima K, Zummo G (2001) Critical heat flux prediction for saturated flow boiling of water in vertical tubes. Int J Heat Mass Transf 44:4323-4331

23. Tanase A, Cheng SC, Groeneveld DC, Shan JQ (2009) Diameter effect on critical heat flux. Nucl Eng Des 239:289-294

24. Karayiannis TG, Shiferaw D, Kenning DB, Wadekar VV (2010) Flow patterns and heat transfer for flow boiling in small to micro diameter tubes. Heat Transfer Eng 31:257-275

25. Harirchian T, Garimella SV (2008) Flow patterns during convective boiling in microchannels. ASME J. Heat Transfer 130(8):080909

26. Lopez de Bertodano MA, Assad A, Beus SG (2001) Experiments for entrainment rate of droplets in the annular regime. Int $J$ Multiphase Flow 27:685-699

27. Kandlbinder T (1998) Experimental Investigation of Forced Convective Boiling of Hydrocarbons and Hydrocarbon Mixtures. Ph.D thesis, University of London

28. Kim CH, Chang SH (2005) CHF characteristics of R-134a flowing upward in uniformly heated vertical tube. Int J Heat Mass Transf 48(11):2242-2249

29. Wu Z, Sundén B, Li W, Wadekar V (2013) Evaporative annular flow in micro/minichannels: a simple heat transfer model. ASME J Therm Sci Eng Appl 5(3):031009

30. Wu Z, Sundén B (2016) Flow-pattern based heat transfer correlations for stable flow boiling in micro/minichannels. ASME J. Heat Transfer 138(3):031501 